CZASOPISMO INŻYNIERII LĄDOWEJ, ŚRODOWISKA I ARCHITEKTURY JOURNAL OF CIVIL ENGINEERING, ENVIRONMENT AND ARCHITECTURE

JCEEA, t. XXXIII, z. 63 (4/16), październik-grudzień 2016, s. 305-314

Piotr KOPEĆ ${ }^{1}$

\title{
CZYNNIKI CHEODNICZE O NISKIM WSPÓŁCZYNNIKU GWP STOSOWANE W POWIETRZNYCH POMPACH CIEPŁA
}

\begin{abstract}
W artykule przedstawiono obecny stan prawny dotyczący czynników chłodniczych stosowanych w pompach ciepła oraz urządzeniach chłodniczych i klimatyzacyjnych a także omówiono ich wpływ na środowisko. Obowiązujące regulacje prawne zawierają plan redukcji stosowania czynników chłodniczych wpływających na ocieplenie klimatu. Następnie dokonano analizy rynku pomp ciepła w Polsce w latach 2010-2015. Szczególną uwagę zwrócono na pompy ciepła pracujące w układzie powietrze-woda, które w 2015 roku odnotowały znaczny wzrost sprzedaży. Wzrost ten wynosił około $70 \% \mathrm{w}$ stosunku do roku 2014. Ze względu na niski koszt inwestycyjny, bardzo duży udział w rynku posiadają powietrzne pompy ciepła przeznaczone do podgrzewania ciepłej wody użytkowej. W związku z regulacjami prawnymi, dobór odpowiedniego czynnika chłodniczego staje się trudnym zagadnieniem. Należy bowiem dobrać czynnik chłodniczy, który będzie zarówno bezpieczny dla środowiska oraz będzie posiadał bardzo dobre właściwości termodynamiczne. Przedstawiono właściwości idealnego czynnika chłodniczego oraz kryteria jakimi powinno się kierować przy doborze nowego. Dokonano również porównania proponowanych przez producentów alternatywnych czynników chłodniczych o niskim współczynniku GWP, które mogą być stosowane w powietrznych pompach ciepła. W tym celu założono idealny jednostopniowy sprężarkowy obieg chłodniczy dla pompy ciepła w którym przyjęto stałą temperaturę górnego źródła ciepła, przegrzania i dochłodzenie czynnika. Temperatura dolnego źródła ciepła była zmienienia w zakresie od $-20 \mathrm{C}$ do $+15 \mathrm{C}$. Analizy proponowanych czynników dokonano pod względem zmiany współczynnika wydajności grzewczej COP w stosunku do obecnie stosowanych freonów.
\end{abstract}

Słowa kluczowe: współczynnik COP, R1234yf, rynek pomp ciepła w Polsce, ODP

\section{Wprowadzenie}

Czynnik chłodniczy jest niezbędnym elementem do poprawnego działania pompy ciepła. Pośredniczy on w wymianie ciepła. Pobiera ciepło z dolnego źródła ciepła, wrząc w parowniku w niskiej temperaturze i pod niskim ciśnieniem,

\footnotetext{
${ }^{1}$ Piotr Kopeć, Politechnika Krakowska, Wydział Mechaniczny, Instytut Inżynierii Cieplnej i Procesowej, al. Jana Pawła II 37, 31-864 Kraków, tel. (12) 62834 69, pkopec@ mech.pk.edu.pl
} 
aby później oddać je do górnego źródła ciepła w skraplaczu w procesie skraplania, przebiegającym pod wysokim ciśnieniem i wysokiej temperaturze. Najpopularniejszymi czynnikami stosowanym w sprężarkowych powietrznych pompach ciepła są R134a, R404A, R410A. Z uwagi na oddziaływanie czynników chłodniczych na środowisko obecnie poszukuje się najbardziej optymalnych zamienników dla stosowanych czynników oraz szuka innych nowych, które nie wywierałyby negatywnego wpływu na atmosferę ziemi. W trosce o środowisko i ekologię Parlament Unii Europejskiej wprowadził regulacje prawne dotyczące substancji, które wpływają na wzmożenie efektu cieplarnianego i niszczenie warstwy ozonowej. Obecnie obowiązuje Rozporządzenie Parlamentu Europejskiego i Rady nr 517/2014 z dnia 16 kwietnia 2014 roku. Rozporządzenie odnosi się do fluorowanych gazów cieplarnianych. Głównym celem rozporządzenia jest ochrona środowiska poprzez zmniejszenie emisji fluorowanych gazów cieplarnianych na skutek odzyskiwania czynników, ograniczania bądź zaniechania ich stosowania. Według założeń do 2050 roku emisja gazów cieplarnianych powinna być zredukowana o 80-95\% w odniesieniu do poziomu z roku 1990. Natomiast do 2030 roku poprzez unikanie wykorzystywania fluorowanych gazów cieplarnianych powinna zostać zredukowana ich emisja do $2 / 3 \mathrm{w}$ stosunku do poziomu z 2010 roku. Szczegółowy harmonogram wycofywania z użycia omawianych gazów znajduje się w rozporządzeniu [1].

\section{Rynek pomp ciepła w Polsce}

Pompa ciepła jest jednym z urządzeń, które korzysta z energii odnawialnej. Jej głównym zadaniem jest wykorzystanie niskotemperaturowej energii cieplnej z odnawialnych źródeł energii i przetransportowanie jej na wyższy poziom energetyczny, do wytworzenia ciepła o wyższej temperaturze, przy wykorzystaniu zewnętrznej energii: mechanicznej, cieplnej lub elektrycznej [2]. Pompa ciepła może pobierać energię z różnych rodzajów źródeł niskotemperaturowych. $\mathrm{Z}$ tego też względu klasyfikuje się je na pompy ciepła: gruntowe (poziome, pionowe), powietrzne i wodne.

Rynek pomp ciepła w Polsce systematycznie rośnie. Średni wzrost wynosi około $20 \%$ rocznie. Najbardziej dynamicznie rozwijał się na przełomie roku 2012/2013. W roku 2015 natomiast największy udział w rynku w stosunku do roku poprzedzającego, miały pompy ciepła pracujące $\mathrm{w}$ układzie powietrzewoda. Wzrost sprzedaży wyniósł prawie 70\% [3]. Tak duże zainteresowanie tego rodzaju pompami ciepła wynika z:

- niskich kosztów zakupu i eksploatacji,

- wzrostu efektywności pomp ciepła powietrze-woda,

- zmian w warunkach technicznych dla budynków dokonanych w 2014 roku dotyczących izolacyjności przegród,

- łagodniejszych okresów zimowych w ostatnich latach, 
- większej tendencji do budowania domów o powierzchni nie przekraczającej $130 \mathrm{~m}^{2}$,

- większej świadomości ludzi do korzystania z odnawialnych źródeł energii

Opierając się na badaniach i danych Polskiej Organizacji Rozwoju Technologii Pomp Ciepła (PORT PC), na rysunku 1 przedstawiono ogólną sprzedaż pomp ciepła $w$ Polsce $w$ latach 2010-2015. Natomiast rysunek 2 przedstawia sprzedaż powietrznych pomp ciepła pracujących w układzie powietrze-woda oraz powietrze-woda przeznaczonych tylko do przygotowanie ciepłej wody użytkowej-CWU[3].

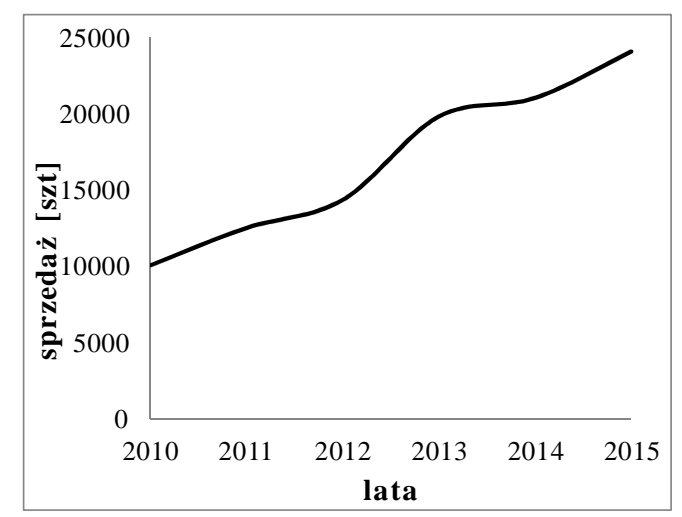

Rys. 1. Sprzedaż pomp ciepła w Polsce w latach 2010-2015, na podstawie [3]

Fig. 1. Sales of heat pumps in Poland in years 2010-2013, based on [3]

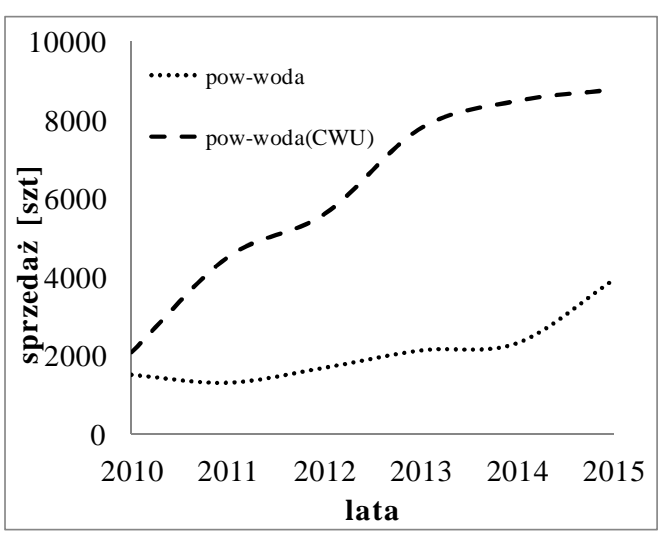

Rys. 2. Sprzedaż powietrznych pomp ciepła w Polsce w latach 2010-2015, na podstawie [3]

Fig. 2. Sales of air heat pumps in Poland in years 2010-2013, based on [3] 


\section{Czynniki chłodnicze o niskim współczynniku GWP}

Nowy czynnik chłodniczy, który jest wprowadzany do użytku jako zamiennik już istniejącego, powinien posiadać lepsze właściwości fizykochemiczne i termodynamiczne, być bezpieczny w użyciu, łatwo osiągalny, tani oraz spełniać odpowiednie wymagania prawne [4]. Kolejnym ważnym aspektem przy wprowadzaniu zamiennego czynnika jest możliwość zastosowania go w istniejącej instalacji chłodniczej, bez ingerencji w jej elementy składowe. Porównując dwie substancje oprócz własności fizykochemicznych, należy również ocenić wskaźniki ekologiczne, które określają w jakim stopniu czynnik chłodniczy wpływa na atmosferę ziemską. Jednym z nich jest współczynnik GWP (Global Warming Potential). Jest to potencjał danego czynnika do tworzenia efektu cieplarnianego. Odniesiony jest do dwutlenku węgla $\left(\mathrm{CO}_{2}\right)$ dla którego wartość GWP $=1$. Jako okres oddziaływania czasowego przyjmuje się 100 lat. Wartość tego współczynnika spowodowała poszukiwania nowych czynników chłodniczych według dyrektywy UE. Kolejny wskaźnik to ODP (Ozone Depletion Potential), czyli wskaźnik określający wpływ danej substancji na rozkład warstwy ozonowej zawartej w atmosferze ziemskiej. Wartość współczynnika ODP odniesiona jest do czynnika chłodniczego R11, dla którego ODP = 1 [5]. Najlepsze z punktu widzenia ekologicznego są czynniki pochodzenia naturalnego lub syntetyczne, których wartości to: $\mathrm{ODP}=0$ oraz GWP $\approx 0$. Podsumowując idealny czynnik chłodniczy powinien posiadać następujące cechy [6]:

- niska normalna temperatura wrzenia,

- wysoka wartość temperatury,

- krytycznej,

- niska temperatura krzepnięcia,

- mała objętość właściwa,

- znikoma rozpuszczalność w wodzie,

- nietoksyczność,

- niewybuchowość,

- niski koszt jednostkowy,

- obojętny dla środowiska naturalnego.

Znalezienie odpowiedniego czynnika, który spełniałby wszystkie cechy jest bardzo trudne. W związku z dużą liczbą produktów oferowanych przez koncerny chemiczne zajmujące się wytwarzaniem substancji, które mogą pełnić rolę czynników chłodniczych powinno się zastosować odpowiednie kryteria doboru. W wyniku regulacji prawnych i dążenia do spełnienia założonych celów na lata 2030 oraz 2050, podczas wyboru czynnika powinno się brać pod uwagę następujące aspekty, wymienione poniżej według ich ważności [6]:

- oddziaływanie na środowisko,

- bezpieczeństwo pracy instalacji,

- własności termodynamiczne,

- własności techniczne,

- kryteria ekonomiczne. 


\subsection{Charakterystyka alternatywnych czynników chłodniczych}

Powszechnie wykorzystywane $\mathrm{w}$ instalacjach klimatyzacyjnych oraz urządzeniach chłodniczych czynniki R134a, R404A, R410A, zostały wprowadzony jako zamiennik freonu R12 oraz R22. Jednak ze względu na przepisy prawne związane $\mathrm{z}$ ochroną środowiska zostaną $\mathrm{w}$ niedalekiej przyszłości wycofane z użytku. Koncerny chemiczne zajmujące się produkcją czynników chemicznych szukają nowych zamienników, które spełniałyby wszystkie wymagania. W literaturze [6], [7], [8], [9] jako alternatywne czynniki chłodnicze, które mogą być stosowane jako zamienniki obecnie już stosowanych wymienia się następujące freony: R1234yf, R290, R32, R513A (Opteon XP10), R449A (Opteon XP40), R452A (Opteon XP44). W tabeli 1 przedstawiono wybrane właściwości omawianych czynników chłodniczych. Analizując tabelę 1, można zauważyć, że czynniki będące zamiennikami już stosowanych mają zbliżone temperatury wrzenia oraz temperatury punktu krytycznego.

Tabela 1. Wybrane właściwości czynników, na podstawie [10]

Table 1. Selected refrigerants properties, based on [10]

\begin{tabular}{|c|c|c|c|c|c|c|}
\hline & $\begin{array}{c}\text { Normalna } \\
\text { temperatura } \\
\text { wrzenia }\left[{ }^{\circ} \mathrm{C}\right]\end{array}$ & $\begin{array}{c}\text { Temperatura } \\
\text { krytyczna } \\
{\left[{ }^{\circ} \mathrm{C}\right]}\end{array}$ & $\begin{array}{c}\text { Zastępowa- } \\
\text { ny czynnik }\end{array}$ & GWP & ODP & Palność \\
\hline R134a & -26 & 101 & $\mathrm{R} 12$ & 1430 & 0 & $\mathrm{~A} 1$ \\
\hline R404a & -47 & 73 & $\mathrm{R} 22$ & 3922 & 0 & $\mathrm{~A} 1$ \\
\hline R410A & -51 & 72 & $\mathrm{R} 22$ & 2088 & 0 & $\mathrm{~A} 1$ \\
\hline R1234yf & -30 & 95 & $\mathrm{R} 134 \mathrm{a}$ & 4 & 0 & $\mathrm{~A} 2 \mathrm{~L}$ \\
\hline R290 & -42 & 97 & $\mathrm{R} 404 \mathrm{a}$ & 3 & 0 & $\mathrm{~A} 3$ \\
\hline R32 & -52 & 78 & $\mathrm{R} 410 \mathrm{a} / \mathrm{R} 12$ & 675 & 0 & $\mathrm{~A} 2 \mathrm{~L}$ \\
\hline R513A & -29 & 98 & $\mathrm{R} 134 \mathrm{a}$ & 631 & 0 & $\mathrm{~A} 1$ \\
\hline R449A & -46 & 82 & $\mathrm{R} 404 \mathrm{a}$ & 1397 & 0 & $\mathrm{~A} 1$ \\
\hline
\end{tabular}

Przy wyborze zamiennika należy również zwrócić uwagę na jego klasę palności. Czynniki o wysokich wartościach współczynnika GWP posiadają klasę palności A1, czyli są nie palne. Czynniki o niskich współczynnikach GWP są słabo palne (klasa A2L), średnio palne (klasa A2), lub łatwopalne (klasa A3). Można zauważyć, że im niższa wartość współczynnika GWP, tym większa palność czynnika. Oznacza to, że im czynnik bardziej bezpieczny dla środowiska, tym mniej bezpieczny dla człowieka. Wymusza to na producentach zwrócenie szczególnej uwagi na bezpieczeństwo użytkowania projektowanych urządzeń oraz wpływa na ograniczenie ilości czynnika chłodniczego w układach chłodniczych. Na rysunku 3 przedstawiono krzywe nasycenia rozważanych czynników w układzie log p-i. Natomiast rysunek 4 przedstawia zależności ciśnienia parowania względem temperatury. 


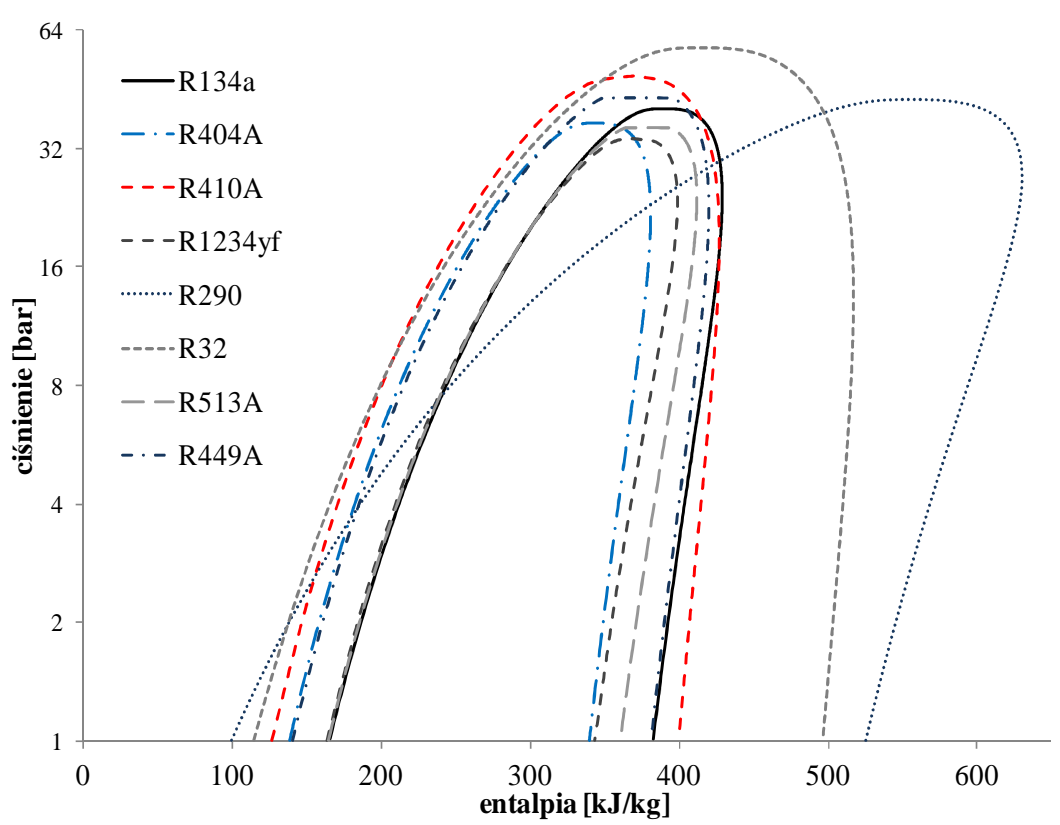

Rys. 3.Krzywe nasycenia analizowanych czynników na wykresie log p-i

Fig. 3. Refrigerant analyzed saturation curve on $\log$ p-i chart

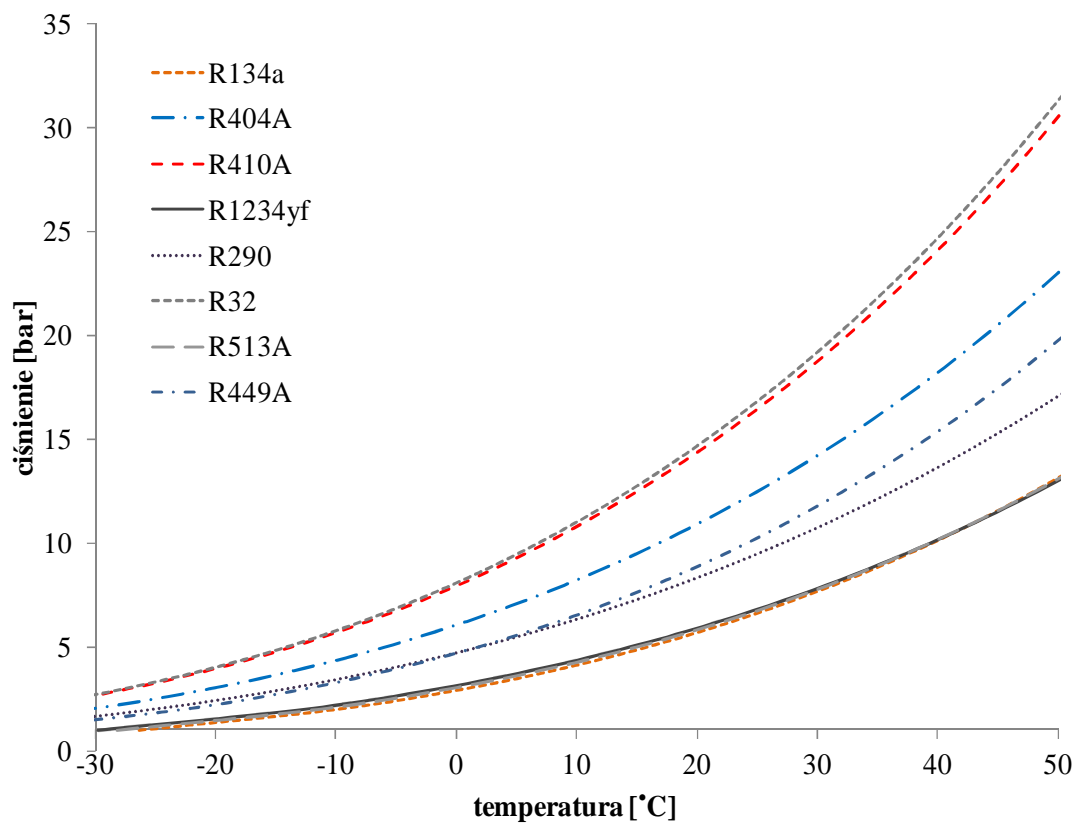

Rys. 4. Zależność cieśnienia parowania względem temperatury

Fig. 4. Dependence of evaporation pressure on temperature 


\section{Porównanie teoretycznych obiegów pomp ciepła z zastosowaniem czynników o niskim współczynniku GWP}

Do porównania idealnych obiegów powietrznych pomp ciepła pracujących z czynnikami o niskim współczynniku GWP przyjęto następujące parametry układu: wydajność grzewczą, temperaturę górnego źródła ciepła, różnicę pomiędzy temperaturą skraplania czynnika chłodniczego a temperaturą górnego źródła ciepła, różnicę pomiędzy temperaturą dolnego źródła ciepła a temperaturą odparowania czynnika ziębniczego, przegrzanie oraz dochłodzenie freonu. Temperaturę dolnego źródła ciepła zmieniano w zakresie od $-20^{\circ} \mathrm{C} \div 15^{\circ} \mathrm{C}$. Przyjęte wartości podano w tabeli 2 . Następnie korzystając z wykresów log p-i porównywanych czynników chłodniczych odczytano wartości entalpii w poszczególnych punktach oraz wyliczono współczynnik wydajności grzewczej COP z zależności (1) - (3).

$$
\begin{gathered}
\dot{m}=\frac{\dot{Q_{K}}}{i_{2}-i_{3}} \\
\dot{N}=\dot{m} \cdot\left(i_{2}-i_{1}\right) \\
C O P=\frac{\dot{Q_{K}}}{\dot{N}}
\end{gathered}
$$

gdzie: $\dot{Q}_{k}-$ wydajność grzewcza pompy ciepła $[\mathrm{kW}]$,

$\dot{N}$ - zapotrzebowanie na moc sprężarki $[\mathrm{kW}]$,

$\dot{m}$ - strumień masy czynnika $[\mathrm{kg} / \mathrm{s}]$,

$i_{1}$ - entalpia czynnika na wylocie parownika, wlot do sprężarki $[\mathrm{kJ} / \mathrm{kg}]$,

$i_{2}$ - entalpia czynnika na wylocie sprężarki, wlot do skraplacza $[\mathrm{kJ} / \mathrm{kg}]$,

$i_{3}$ - entalpia czynnika na wylocie ze skraplacza[kJ/kg],

$C O P$ - współczynnik wydajności grzewczej pompy ciepła [-].

Tabela 2. Parametry obliczeniowe obiegu chłodniczego

Table 2. Calcuation parameters of the refrigerant cycle

\begin{tabular}{|c|c|c|c|c|c|}
\hline$\dot{Q}_{k}[\mathrm{~kW}]$ & $\mathrm{T}_{\mathrm{G}}\left[{ }^{\circ} \mathrm{C}\right]$ & $\Delta \mathrm{T}_{\mathrm{G}}[\mathrm{K}]$ & $\Delta \mathrm{T}_{\mathrm{D}}[\mathrm{K}]$ & $\Delta \mathrm{T}_{\mathrm{SH}}[\mathrm{K}]$ & $\Delta \mathrm{T}_{\mathrm{SC}}[\mathrm{K}]$ \\
\hline 10 & 35 & 5 & 10 & 5 & 5 \\
\hline
\end{tabular}

$\dot{Q}_{k}$ - wydajność grzewczą, TG - temp. górnego źródła ciepła, $\Delta \mathrm{T}_{\mathrm{G}}$ różnica pomiędzy temperaturą górnego źródła ciepła a temperaturą skraplania czynnika, $\Delta \mathrm{T}_{\mathrm{D}}$ różnica pomiędzy temperaturą dolnego źródła ciepła a temperaturą odparowania, $\Delta \mathrm{T}_{\mathrm{SH}}$ przegrzanie, $\Delta \mathrm{T}_{\mathrm{SC}}$ dochłodzenie. 
Na rysunku 5 przedstawiono otrzymane wartości współczynników COP dla pompy ciepła pracującej na czynnikach o niskich wartościach GWP w różnych temperaturach dolnego źródła ciepła. Można zauważyć, że największe współczynniki COP uzyskuje się dla czynnika R134a. W przypadku stosowania czynników R1234yf oraz R513a o niskim współczynniku GWP zaproponowanych jako zamienniki R134a uzyskuje się niższe wartość COP średnio o około $4 \%$ dla R1234yf i 2\% dla R513a. Drugim czynnikiem, który uzyskał wysokie wartości COP jest propan (R290). W literaturze często wymieniany jest jako zamiennik R404a. Wartości COP dla R290 są średnio o około 8\% wyższe niż dla R404a. Z pośród porównywanych czynników najniższe wartości COP uzyskał czynnik R449a, zamiennik dla R404a. Wartości COP jaki uzyskano dla porównywanego układu z tym czynnikiem były niższe średnio o $5 \%$ w porównaniu do R404a.

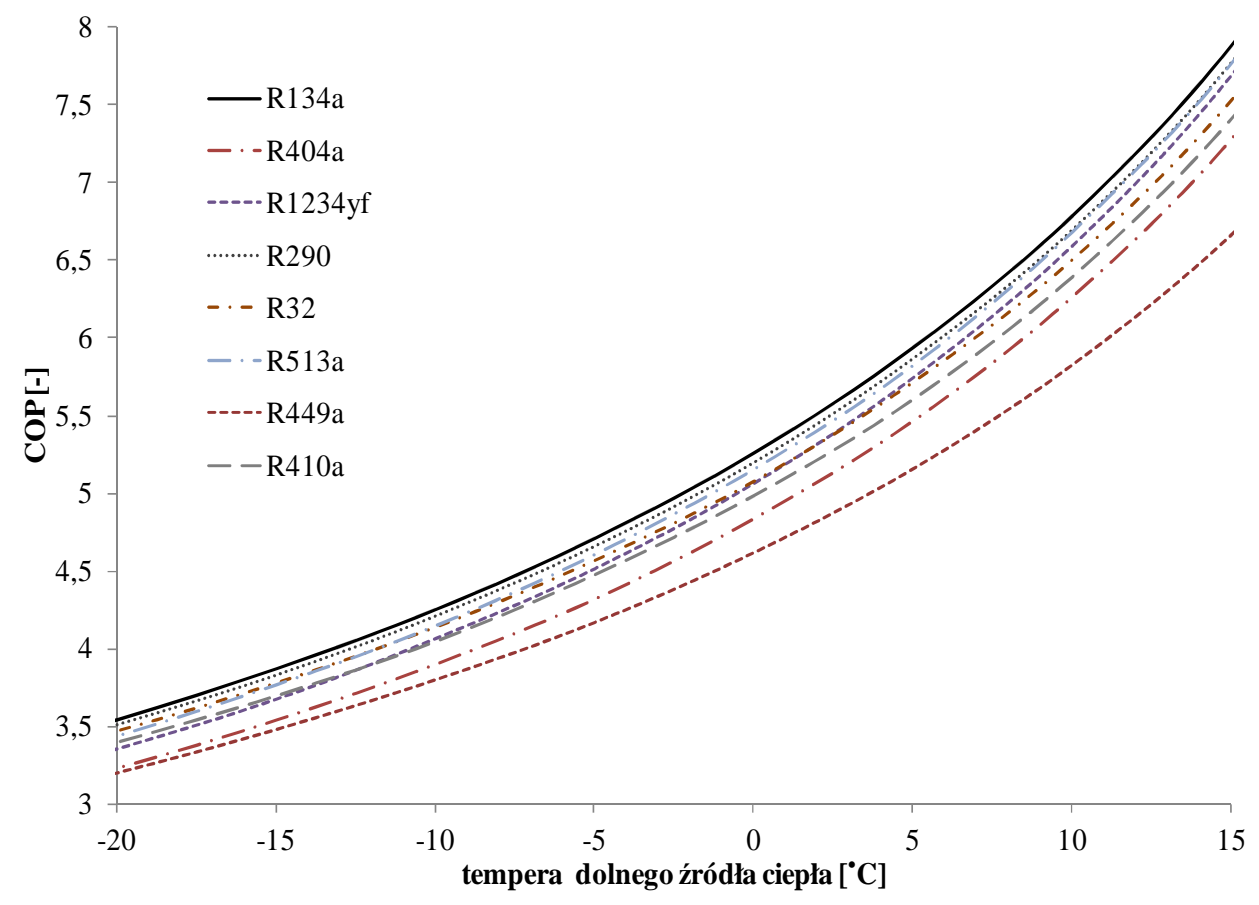

Rys. 5. Zależność współczynnika COP od temperatury dolnego źródła ciepła

Fig. 5. The dependence COP factor of the heat source temperature 


\section{Podsumowanie}

Dobór odpowiedniego czynnika dla układu pompy ciepła nie jest zagadnieniem łatwym. Należy pogodzić ze sobą trzy aspekty: wydajność urządzenia, bezpieczeństwo dla środowiska oraz bezpieczeństwo użytkownika i wybrać optymalny czynnik. Troska o środowisko oraz spełnianie wymagań legislacyjnych wymusza na producentach stosowanie w układach chłodniczych czynników o niskich współczynnikach GWP. Z drugiej strony klient wymaga od produktu jak największej efektywności pracy. W przypadku analizowanych czynników, nowe substancje są bezpieczniejsze dla środowiska i osiągają na ogół niższe wartości współczynników COP, jednak różnica ta nie przekracza więcej niż 5\%. Bardzo dobrym zamiennikiem wydaje się być czynnik R290. Uzyskał one wyższe wartości współczynnika COP, w stosunku do R404a. Minusem jest wyższa klasa palność. Wpływa to niestety negatywnie na bezpieczeństwo użytkownika. Zamiany czynników na początku zawsze wywołują kontrowersję i wzbudzają obawę, jednak należy szukać nowych substancji i wprowadzać je do użytku z uwagi na to, że problem ocieplania klimatu jest problemem globalny i posiada długi horyzont czasowy.

\section{Literatura}

[1] Rozporządzenie Parlamentu Europejskiego i Rady (UE) NR 517/2014 z dnia 16 kwietnia $2014 \mathrm{r}$.

[2] Zalewski W.: Pompy ciepła sprężarkowe, sorpcyjne i termoelektryczne, IPPU Masta, Gdańsk 2001.

[3] PORT PC: Spektakularny wzrost rynku powietrznych pomp ciepła w 2015 roku, Chłodnictwo \& Klimatyzacja, nr 1-2 (204), 2016, s. 31-32.

[4] Wesołowski A., Kontrowersje związane z R1234yf jako czynnikiem chłodniczym, Chłodnictwo \& Klimatyzacja , nr. 10 (146), 2010, s. 16-19.

[5] Bonca Z., Butrymowicz D., Dambek D., Targański W., Poradnik Czynniki chłodnicze i nośniki ciepła - własności cieplne, chemiczne i eksploatacyjne., IPPU Masta, 1998.

[6] Bohdal T., Charun H., Kuczyński W.:Analiza wyboru czynników roboczych dla sprężarkowych wysokotemperaturowych powietrznych pomp ciepła. Chłodnictwo, nr. 9, 2015, s. 24-32.

[7] Bohdal T., Charun H., Sikora M.: Wybrane aspekty prawno-techniczne I ekologiczne stosowania sprężarkowych pomp ciepła. Annual Set The Environment Protection, vol.17, 2015, p. 461-484.

[8] Targański W.: Alternatywne syntetyczne czynniki chłodnicze. Chłodnictwo \& Klimatyzacja, nr 1-2 (204), 2016, s. 58-61.

[9] Kałuża J., Zasada D.: Co nowego w sprawie F-gazów? Chłodnictwo \& Klimatyzacja, nr. 4 (206), 2016, s.10-11.

[10]Czynniki chłodnicze - raport bitzer wydanie 18 . 


\section{LOW GWP REFRIGERANTS APPLIED IN AIR HEAT PUMP}

\section{S u m m a r y}

The paper presents the current legal situation of the refrigerants used in heat pumps, refrigeration and air conditioning systems, it also discusses their impact on the environment. Regulations include a plan to reduce the use of refrigerants that influence on global warming. Moreover, in the article was made the analysis of the heat pump market in Poland in the years 2010-2015. Particularly attention was paid to the air-water heat pump, which in 2015 recorded increase in sales. The increase was approximately $70 \%$ compared to 2014 . Due to the low investment cost, air-water heat pump only for utility hot water have a large market share. Selection of a suitable refrigerant becomes a difficult issue, because of the regulations. The chosen refrigerant should be safe for environment and had very good thermodynamic properties. Additionally, show properties of ideal refrigerant and the criteria which should be consider in the selection process of new refrigerant. Furthermore was made a comparison of suggested alternative refrigerant with low GWP, which can be used in air heat pumps. For this comparison, it was assumed ideal single stage refrigerant cycle for the heat pump with constant heat sink temperature, superheating and subcooling of refrigerant. Temperature of heat source was in the range of $-20 \mathrm{C}$ to $+15 \mathrm{C}$. The analysis of the proposed refrigerants has been made in changing the coefficient of performance COP compared to the currently used refrigerants.

Keywords: COP factor, R1234yf, heat pump market in Poland, ODP

DOI:10.7862/rb.2016.275

Przestano do redakcji: 19.05.2016r.

Przyjęto do druku: 20.12.2016 r. 